\title{
CLINICAL RELEVANCE OF HETEROTOPIC OSSIFICATION OF HIP AND PELVIC BONES MUSCLES AND LIGAMENTS
}

\author{
SUMITA AGARWAL* \\ Department of Anatomy, People's College of Medical Sciences and Research Centre, Madhya Pradesh, India. \\ Email: docsumita29@gmail.com
}

Received: 12 November 2021, Revised and Accepted: 25 December 2021

\begin{abstract}
Objectives: Heterotopic ossification is a formation of bone at unusual sites. The present study is aimed to observe the ossification of transverse acetabular ligament, obturator membrane and gluteus maximus muscle in hip bones and fibrous capsule of hip joints and ossification of sacrotuberous and sacrospinous ligaments, erector spinae aponeurosis in pelves, and bilateral ankylosis of sacroiliac joints.

Methods: The study was performed on 128 dried human hip bones and six pelves of unidentified sex and age, in the Department of Anatomy. An ossified muscles and ligaments of hip and pelvic bones were observed and their measurements were recorded using Vernier calipers.

Results: The present study showed the incidence of completely ossified transverse acetabular ligament in four hip bones, that is, $3.12 \%$ with completely ossified fibrous capsule of hip joint on the left side. The incidence of bony spurs along the margin of Obturator Foramen in four left hip bones is $6.25 \%$ along with the ossification of the gluteus maximus muscle on dorsal aspect of ilium. Out of six pelves, one pelvis presented complete ossification of erector spinae aponeurosis bilaterally on the dorsal surface of the sacrum along with complete ossification of sacrotuberous ligament of the right side and sacrospinous ligament of the left side along with bilateral ankylosed sacroiliac joint of pelvis.
\end{abstract}

Conclusions: The knowledge of these abnormal ossifications of hip bones and pelvis may be of immense help to orthopedicians, surgeons, neurosurgeons, and radiologists to come to differential diagnosis and plan treatment accordingly.

Keywords: Heterotopic ossification, Sacrotuberous ligament, Transverse acetabular ligament, Erector spinae aponeurosis.

(C) 2022 The Authors. Published by Innovare Academic Sciences Pvt Ltd. This is an open access article under the CC BY license (http://creativecommons.org/ licenses/by/4.0/) DOI: http://dx.doi.org/10.22159/ajpcr.2022v15i2.43707. Journal homepage: https://innovareacademics.in/journals/index.php/ajpcr

\section{INTRODUCTION}

The bony pelvis, a large basin-like structure comprising of sacrum, coccyx, and a paired hip bones meant for stabilizing and weight transmission from axial skeleton to the lower limbs while the hip bones connect lower limbs to the pelvic girdle along with pelvic muscles and ligaments meant for stability of the joint compromising range of movement. These joints show varieties of degenerative diseases of joint and ankylosis associated with age and persistent cross legged, squatting postures acquired throughout life.

Heterotopic ossification is an abnormal healing process after post-traumatic injury of joints and soft tissue where formation of lamellar bone inside soft tissue occurs at the site of inflammation which stimulates osteoprogenitor cells to proliferate as primitive mesenchymal cells in the connective tissue transform into osteoblastic tissues and osteoids [1]. The joints such as the hip, knee, elbow, and shoulder are more susceptible to heterotopic ossification.

In 1962, Patin was the first to describe heterotopic ossification in children with myositis ossificans progressive [2]. At ectopic sites, bone morphogenic protein shows osteoinducive properties of bones described by Marshall Urist, considered as landmark discovery in orthopedic research [3]. Many conditions such as ankylosing spondylitis, rheumatoid arthritis, hypertrophic osteoarthritis, and diffuse idiopathic skeletal hyperostosis are found in concurrence with heterotopic ossification.

The present study is aimed to observe the ossification of transverse acetabular ligaments, obturator membrane and gluteus maximus muscle in hip bones and fibrous capsule of hip joints and ossification of sacrotuberous, sacrospinous ligaments, erector spinae aponeurosis muscles in pelves, and bilateral ankylosis of sacroiliac joints.

\section{METHODS}

The study was performed on 128 ( 66 of right and 62 of left) dried human hip bones and six pelves of unidentified sex and age, in the Department of Anatomy, at Peoples College of Medical Sciences and research, Bhopal and at Government Doon Medical College, Dehradun, India. Fractured and damaged hip and pelvic bones were excluded from the study.

The hip bones and Pelves were examined for ossification of ligaments, muscles and capsule of the joints, and photographs of specimens were taken. Measurements of ossified sacrotuberous ligament, sacrospinous ligament, and transverse acetabular ligament were recorded using Vernier calipers by a single observer to have better precision in measurements and the data were tabulated. To calculate percentage, data were subjected to MS EXCEL 2007 for statistical analysis.

\section{RESULTS}

In the present study, the hip bones showed the incidence of completely ossified transverse acetabular ligament in $3.12 \%$ of hip bones as four hip bones; two of the right and two of the left side out of 128 hip bones (Fig. 1) which may compress the acetabular branches of obturator and medial circumflex femoral vessels causing ischemia along with completely ossified acetabular labrum. The left-sided hip bone also showed completely ossified fibrous capsule of hip joint. These abnormal ossifications may obstruct or minimize the range of movements of hip joint along with pain compressing the neurovascular structures supplying the joint.

In four left hip bones, out of 62 , that is, $6.45 \%$, bony spurs were present along the margin of obturator foramen which indicated the initiation of ossification of obturator membrane along the line of attachment (Fig. 2). 
The left hip bone showed the ossification of the gluteus maximus muscle on dorsal aspect of ilium which extended to the posterior border of ilium.

Out of six pelves, in one pelvis completes ossification of erector spinae aponeurosis and was present bilaterally on the dorsal surface of the sacrum (Fig. 3). As it is a powerful extensor of spine and may undergo muscle strain or any injury of muscle fibers. On healing, formation of immature bone cells at the injury site replacing fibroblast cells. Complete ossification of sacrotuberous ligament of the right side and sacrospinous ligament of the left side (Fig. 3) compromising the movements of sacroiliac joint. Based on the knowledge of anatomy, lesser sciatic foramen formed between the above two ligaments may be reduced in size entrapping the neurovascular structures as pudendal nerve, nerve to obturator internus, and internal pudendal vessels. Pudendal nerve being the chief sensory nerve supply of perineum and external genitalia leads to pain and numbness in perineal region.

Bilaterally ankylosed sacroiliac joint of pelvis (Fig. 3) which transmits the weight of the body to the lower extremity through sacrum strengthened by various ligaments as ventral and dorsal sacroiliac ligaments, iliolumbar ligament, and the second strongest ligament of
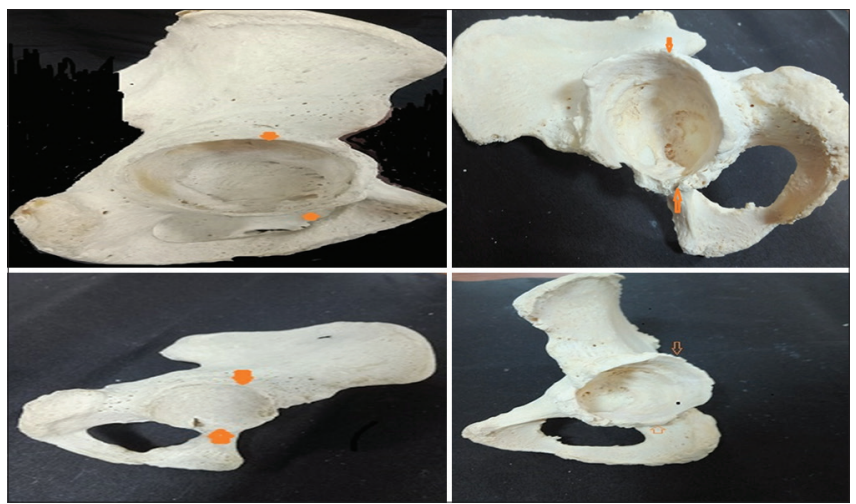

Fig. 1: Upward pointing arrow showing ossified transverse acetabular ligament and downward pointing arrow showing ossified acetabulare labrum in hip bone

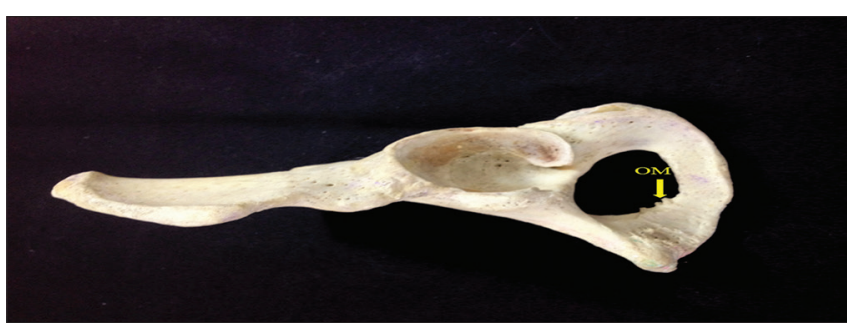

Fig. 2: Hip bone showing bony projections of ossified obturator membrane muscle the body known as interosseous sacroiliac ligament not only meant for body weight transmission but in females provide bony support to the birth canal. Fusion of the sacroiliac joints not only hampering the movements of the joint but can also cause difficult parturition.

The other pelvis showed initiation of sacrotuberous ligaments ossification (Fig. 4) on both side with width of $2.3 \mathrm{~cm}$.

Such a wide range of ossification manifesting as various clinical conditions are of immense help and significance to the anthropologists, anesthetists, surgeons, and radiologists to diagnose the disease at its earliest as well as to accurately interpret the computed tomography (CT) and magnetic resonance imaging (MRI) scans (Table 1).

\section{DISCUSSION}

The bone formation at an extra skeletal tissue sites is heterotopic ossification that results from either genetically or post-traumatic injury.

Abnormal ossified structures around the hip joint were noted by Chakravarthi et al. [4] as unilateral ossified acetabular labrum with ossified transverse acetabular ligament in seven right hip bones with very rare and peculiar unilateral ossified and complete fused left hip.

Perumal et al. [5] reported complete ossification of transverse acetabular ligament in five hip bones out of 114 . Incomplete
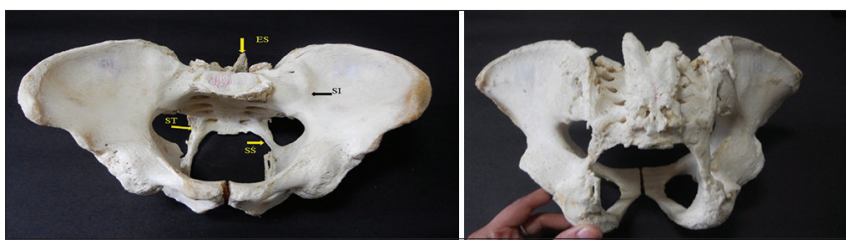

Fig. 3: Pelvis (ventral and dorsal views) showing ossified erector spinae aponeurosis and both left sacrospinous and right sacrotuberous ligaments as well as bilaterally ankylosis of sacroiliac joints

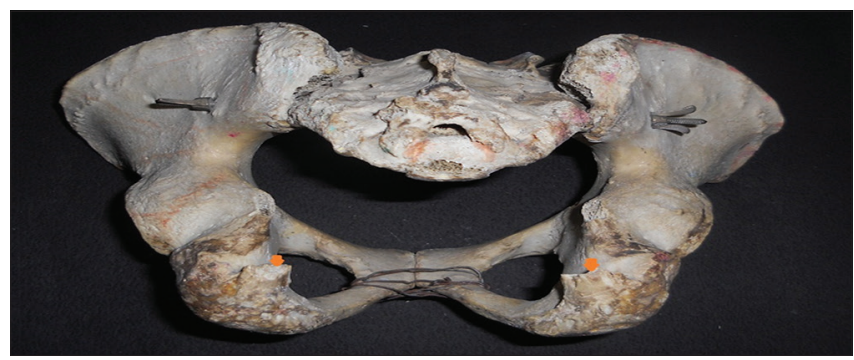

Fig. 4: Pelvis showing initiation of ossified sacrotuberous ligaments on both the sides

Table 1: Ossified ligaments and muscles with their measurements

\begin{tabular}{|c|c|c|c|c|}
\hline \multirow[t]{2}{*}{ Ligament/muscle ossified } & \multicolumn{2}{|l|}{ Number of cases } & \multicolumn{2}{|c|}{$\begin{array}{l}\text { Measurements of complete ossified } \\
\text { ligaments (in } \mathrm{cm})\end{array}$} \\
\hline & Complete ossification & Partial ossification & Maximum $(L \times B)$ & Minimum $(L \times B)$ \\
\hline $\begin{array}{l}\text { Transverse acetabular } \\
\text { ligament }\end{array}$ & four (two right and two left) & - & $5 \times 1.8$ & $4.2 \times 1$ \\
\hline $\begin{array}{l}\text { Acetabular labrum with hip } \\
\text { joint fibrous capsule }\end{array}$ & four (two right and two left) & - & - & - \\
\hline Gluteus maximus muscle & - & One (left) & - & - \\
\hline Erector spinae aponeurosis & One (bilaterally) & - & - & - \\
\hline Sacrotuberous ligament & One (right) & One (bilaterally) & $8.6 \times 1.5$ & \\
\hline Sacrospinous ligament & One (left) & - & $6.4 \times 1.3$ & \\
\hline
\end{tabular}


ossification was noted in 27 of 214 bones, while in the present study, four hip bones out of 128 , that is, $3.12 \%$ showed complete ossification of transverse acetabular ligament along with acetabular labrum and the left-sided hip bone also showed complete ossification of fibrous capsule of hip joint may compromise the movements and the stability of the hip joint.

According to the Ninomiya et al. [6] and Corten et al. [7], ossification of the labrum originates at the subperiosteal region of the outer acetabular rim as a result of pre-existing femoroacetabular impingement.

Papaioannou et al. [8] presented a case report on bilateral, linear calcifications of the gluteal muscles, more prominent on the right, and adjacent to the anatomic site of the sacral nerve of a male patient with 74 years of age with final diagnosis as myositis ossificans of the gluteal muscles, while in the present study, we observed the left hip bone showed the ossification of the gluteus maximus muscle on dorsal aspect of ilium which extended to the posterior border of ilium. Four left hip bones, that is, $3.12 \%$ showed bony spurs along the margin of obturator foramen which indicated the initiation of ossification of obturator membrane along the line of attachment.

Prescher et al. [9] observed ossification of the sacrotuberous ligament in eight pelvic bones out of 101 . The length of ossification was varied ranging from 1.1 to $7.2 \mathrm{~cm}$.

Beyth et al. [10] observed a similar case of myositis ossificans circumscripta involving sacrotuberous ligament.

Arora et al. [11] have reported one case of partial ossification of sacrotuberous ligament in a dried hip bone.

Tirpude et al. [12] presented a case report on pelvis with partially ossified left sacrotuberous ligament of length $54.0 \mathrm{~mm}$ and bilateral ossified transverse acetabular ligaments of which completely ossified on the right side measuring $31.2 \mathrm{~mm} \times 5.6 \mathrm{~mm}$ and incomplete on the left side measuring $15.8 \mathrm{~mm} \times 4.9 \mathrm{~mm}$.

Goddyn et al. [13] observed a case of partial ossification of sacrospinous ligament which caused compression of proximal part of sciatic nerve resulting in sciatica but in the present study observed a pelvis with complete ossification of the right sacrotuberous ligament measuring $8.6 \mathrm{~cm} \times 1.5 \mathrm{~cm}$ with complete ossification of the left sacrospinous ligament measuring $6.4 \mathrm{~cm} \times 1.3 \mathrm{~cm}$ with bilateral ossification of erector spinae aponeurosis along with bilaterally ankylosed sacroiliac joint and initiation of bilateral sacrotuberous ligament ossification in another pelvic bone.

\section{CONCLUSIONS}

The awareness of these abnormal ossifications of hip bones and pelvis may be of immense help to orthopedicians, surgeons, neurosurgeons, and radiologists to come to differential diagnosis by interpreting CT scans and MRI and plan surgical approach accordingly to avoid postoperative hazards and perform reconstructive surgeries

\section{ACKNOWLEDGMENT}

The author acknowledges the Department of Anatomy of both the institutions.

\section{AUTHORS CONTRIBUTION}

Self.

\section{CONFLICTS OF INTEREST}

$\mathrm{Nil}$.

\section{SOURCE OF FUNDING}

Nil.

\section{REFERENCES}

1. Firoozabadi R, Alton T, Sagi HC. Heterotopic ossification in acetabular fracture surgery. J Am Acad Orthop Surg 2017;25:117-24.

2. Bossche LV, Vanderstraeten G. Heterotopic ossification: A review. J Rehabil Med 2005;37:129-36.

3. Pape HC, Marsh S, Morley JR, Krettek C, Giannoudis PV. Current concepts in the development of heterotopic ossification. J Bone Joint Surg Br 2004;86:783-7.

4. Chakravarthi KK, Siddaraju SS, Venumadhav N, Bali SA. Abnormal ossified structures around the hip joint and its clinical implications. Int J Res Med Sci 2017;5:5391-5.

5. Perumal A, Sathiya S. Ossified transverse acetabular ligament-an osteological study. Int J Curr Res Rev 2014;6:37.

6. Ninomiya S, Shimabukuro A, Tanabe T, Kim YT, Tachibana Y. Ossification of the acetabular labrum. J Orthop Sci 2000;5:511-4.

7. Corten K, Ganz R, Chosa E, Leunig M. Bone apposition of the Acetabular rim in deep hips: A distinct finding of global pincer impingement. J Bone Joint Surg 2011;93:10-6.

8. Papaioannou G, Tavernaraki K, Kelekis DA. Myositis Ossificans of the Gluteal Muscles, European Radiology, Case 3091; 2008.

9. Prescher A, Bohndorf K. Anatomical and radiological observations concerning ossification of the sacrotuberous ligament: Is there a relation to spinal diffuse idiopathic skeletal hyperostosis (DISH)? Skeletal Radiol 1993;22:581-5.

10. Beyth S, Liebergall M, Mosheiff R. Myositis ossificans circumscripta of the sacrotuberous ligament: A case report and review of literature. J Orthop Trauma 2002;16:672-4.

11. Arora J, Mehta V, Suri RK, Rath G. Unilateral partial ossification of sacrotuberous ligament: Anatomico-radiological evaluation and clinical implications. Rom J Morphol Embryol 2009;50:505-8.

12. Tirpude A, Mishra P, Gaikwad M, Ravi PK, Jain M. Indiscriminate ossification of ligaments in a dry adult human male pelvis-a rarity. Indian J Clin Anat Physiol 2018;5:280-4

13. Goddyn C, Passuti N, Leconte R, Redon H, Gouin F. Sciatic nerve compression related to ossification of the sacrospinous ligament secondary to pelvic balance abnormalities. Orthop Traumatol Surg Res 2009;95:645-8. 